\title{
Assessing Primary and Lower Secondary School Efficiency Within Northern, Central and Southern Italy
}

\author{
Giuseppe Di Giacomo • Aline Pennisi
}

Received: 23 March 2013 / Accepted: 5 June 2014 / Published online: 12 December 2014

(C) Società Italiana degli Economisti (Italian Economic Association) 2014

\begin{abstract}
This paper explores the efficiency of primary and lower secondary schools in Italy from a productivity perspective. Inputs are related to human and financial resources of schools and outputs represent the achievement in math and reading of their students. The analysis is conducted on a statistical sample of more than a thousand primary and lower secondary schools. We use data envelopment analysis to estimate efficiency and a second-stage model to identify its determinants. Keeping inputs constant, the estimated efficiency distributions indicate there are greater margins of improvement in primary education respect to lower secondary education. In both levels of education, potential productivity gains are particularly large in the South. Factors determining efficiency vary according to the geographical area. A general result is that critical financial management issues have no role in determining efficiency while contextual factors do (despite the fact that the school's average social and economic background is specified in the model as an input). Finally, in the South, being a comprehensive rather than a specialized school can be a factor of inefficiency; this may point out to emerging difficulties in the implementation of legislative provisions directed to rationalizing the school system.
\end{abstract}

Keywords Efficiency - Productivity - Data envelopment analysis - Economies of scale $\cdot$ Resource allocation $\cdot$ Educational economics

JEL Classification $\mathrm{I} 21 \cdot \mathrm{I} 22 \cdot \mathrm{H} 52 \cdot \mathrm{H} 83 \cdot \mathrm{D} 24$

The authors wish to thank the Italian Ministry of Education and INVALSI for providing relevant data and
two anonymous referees for their useful suggestions. An earlier version of this work was circulated as
working paper of the Ministry of Economy and Finance, State General Accounting Department. The
views expressed in the paper are those of the authors and not necessarily reflect those of their institution.

G. Di Giacomo $(\bowtie) \cdot$ A. Pennisi

Rome, Italy

e-mail: giuseppe.digiacomo@tesoro.it 


\section{Introduction}

The Italian school system is essentially public and highly centralized as concerns both financial and regulatory aspects. The central government covers teacher and staff salaries and their recruitment, while local governments support the costs for school buildings and their maintenance (provinces when it comes to higher secondary schools and municipalities in the case of primary and lower secondary schools). Regions plan the school network and calendar.

Despite the fact that the allocation of resources to schools is based on uniform parameters across the country, in recent years international and national assessments have highlighted significant regional differences in student performance in areas such as reading, math, science, and problem solving and a remarkable variability of results between individual schools in the same region. Even in lower branches of education, where there is a single track, between-school variance is particularly large: up to 45 percent of the total variance for both reading and math scores in the 2009-2010 INVALSI (Italian national institute for the evaluation of the school system) national standard assessment for grade 8. This means that, beyond the typical North-South divide, attending one school or another can result in significantly different outcomes (Bratti et al. 2007; Ministero dell'economia e delle finanze, Ministero della Pubblica Istruzione 2007). The difference is particularly pronounced in the South, where the share of between-school variance on the total is equal to $60.6 \%$ for mathematics and $55.8 \%$ for reading, compared to well lower values for the North and Central regions, respectively 18.3 and $40.1 \%$ for math and 22.6 and $38.7 \%$ for reading (INVALSI 2010).

The high variability of results between schools suggests that there is scope for improving of efficiency at the school level. Although public schools do not intervene directly in the recruitment and basic remuneration of staff, since the late nineties they have taken over a certain degree of autonomy. ${ }^{1}$ Indeed, schools are directly responsible for running ordinary services and they may actively promote educational initiatives, by carrying out specific projects and/or modifying the annual teaching schedule up to 20 percent of the standard curriculum. Principals represent the school in labor relations with trade unions, concerning for example additional pay. They recruit and contract short-term substitute teachers, handle allowances to members of state exam committees, and provide for other teacher subsidiary payments. Schools also exert some influence on other matters that could have an impact in educational terms such as class size, teaching materials, and the availability of extra-curricular activities.

The central governments' annual contribution to schools is roughly 41 billion euro for salaries ${ }^{2}$ plus 3 billion for running costs, with reference to the year 2010. The latter are transferred to schools on the basis of parameters and criteria established at the ministerial level. School budgets are mainly funded by the central government

\footnotetext{
1 In particular since Law 59/1997 (known as "Bassanini Law") and subsequent provisions outline the contours of educational institutions' autonomy.

2 Teachers' salaries are determined by bargaining at the national level and paid directly by the central government. The salary brackets progression is slow, limited and mainly conditioned on further service. However, additional second-level bargaining is carried out directly at the school level.
} 
(which accounts for approximately 69 percent of the overall school revenues), followed by individuals and families (18 percent), and municipalities, provinces and regions (about eight percent). The residual share of revenues comes from multiple and more volatile sources, among which a noteworthy contribution has come from the European Union and other international bodies, through grants for cultural exchange or regional development programs (and in this case they have been directed especially to schools in the Southern regions).

In 2010, there were about 10.5 thousand public schools in Italy scattered across 42 thousand service delivery points. Over the years, with an aim to trim down costs and improve efficiency of education expenditure, mergers between schools of the same educational cycle (horizontally) or even of different cycles (vertically) have been sought. Traditionally, primary (grade 1-5) and lower secondary (grade 6-8) education were delivered in separate schools. Today schools "specialized" in primary or in lower secondary education exist alongside the so called "comprehensive" schools, which cover all grades from pre-school to lower secondary. The idea driving this integration is that student learning can benefit from a more continuous educational framework and scale economies can be realized as well. Merging schools across different grades was originally promoted under Law 97/1994 and subsequent provisions. Although there is little evidence on whether comprehensive schools yield better results in terms of performance and efficiency, legislation (Decree Law 98/2011) attempts in making them compulsory for schools under a certain size (i.e., under 1,000 students or 500 in special cases, such as schools in small islands, in mountain communities or in geographic areas characterized by cultural minorities).

This work aims to contribute to the debate by exploring efficiency of primary and lower secondary schools in a productivity perspective. Input factors are directly related to the allocation of financial and human resources in schools and to the socioeconomic and cultural background of students, while output measures are related to student performance. Given a strong between-school variance in school performance, we investigate whether some schools manage outputs better than others with the same inputs and then identify factors that explain these differences.

Unlike the Italian case, for which empirical evidence on the subject is still sporadic, the international literature on this subject is growing and various approaches are used to analyze the efficiency of schools using both non-parametric techniques, such as data envelopment analysis (DEA) and free disposal hull (FDH), and parametric techniques based on stochastic frontier analysis (SFA).

The literature features a wide diversity with regard to the choice of both inputs and outputs. As for inputs, a first strand of work is based mainly on human resources, i.e. the number of teachers and technical and administrative staff employed by schools (Essid et al. 2009; Oliveira and Santos 2005; Maragos and Despotis 2004; Barbetta and Turati 2003). Other work focuses on the provision of financial resources and equipment (Agasisti 2009; Aaltonen et al. 2006), while a third line also includes variables relating to socio-economic and cultural background of students or the school (Agasisti et al. 2012; Tyagi et al. 2008; Portela and Camanho 2007; Mancebon-Torrubia et al. 2010; Ruggiero and Vitaliano 1999).

Outputs typically try to capture school outcomes in terms of student performance, but only a limited number of studies refer to direct measurements of skills or com- 
petence levels (Agasisti 2009; Mancebon-Torrubia et al. 2010). Most contributions use indirect measures such as the share of students which passed the exams or average grades achieved by students in specific disciplines or the share of students who continued their studies.

The unit of analysis does not always coincide with the school but may refer to the level of government responsible for the organization of the education service such as municipalities or school districts (Ruggiero 1996; Aaltonen et al. 2006). Most contributions focus on a specific school cycle (the primary or secondary) and usually refer to a limited sample of schools. These are often schools of a same region or specific area (Barbetta and Turati 2003; Tyagi et al. 2008; Maragos and Despotis 2004; Ruggiero 1996; Ruggiero and Vitaliano 1999) or small national samples (usually $<500$ schools).

Depending on the topic of specific interest, some researchers explore whether environmental, geographical and socio-economic factors play a role in school efficiency (Oliveira and Santos 2005; Tyagi et al. 2008; Aaltonen et al. 2006; Portela and Camanho 2007); others study the effects of increasing competition between schools or promoting greater managerial autonomy (Bradley et al. 2001, Bradley and Taylor 2008) and, still others, investigate the role of structural features (typically school size) or ownership (private/public/nonprofit). The competition theme is particularly developed in the Anglo-Saxon literature and, in particular, in the debate around introducing quasi-markets in the school system.

Previous analysis on the Italian case are limited. Barbetta and Turati (2003) deal with the efficiency of lower secondary schools in Piedmont and verify whether the ownership structure of schools (public, private for-profit and nonprofit) accounts for its efficiency. They suggest that non-profit private schools are generally more efficient than public ones but note a possible skimming effect, whereby students with greater performance concentrate in the most efficient schools. For example, in their data, public schools have a higher number of disabled students compared to private schools. On the same line, Agasisti (2009) concludes competition has a positive impact on the efficiency of Italian high schools, using the average OECD PISA-2006 score in science and mathematics as the output variable.

While estimating the efficiency of primary and lower secondary schools with a DEA technique on samples of over 1,000 schools, this paper introduces some novelty. First, it considers among the output variables the results in math and reading according to the INVALSI standard national assessment. Secondly, it uses detailed information from school budgets allowing an insight not only on the amount of expenditure managed, but also on possible financial difficulties schools face. Third, it focuses on the identification of determinants of efficiency related to the territorial dimension (with particular reference to the geographical location of schools and degree of urbanization), the type of school organization (comprehensive schools or "specialized" only in primary or secondary education), the management capacity, and the composition of school spending and funding sources.

The paper is organized as follows: the next section presents the data and methods used to measure the relative efficiency of each school and the variables used in estimating the empirical model; the third section presents the main results, and the last section provides some policy indications, including discussion on how efficiency 
measurement can be used to promote benchmarking exercises between schools and push the system towards better outcomes with the same amount of resources.

\section{Data and methods}

Estimates of efficiency of production units are generally based on two approaches: data envelopment analysis (DEA) and stochastic frontier analysis (SFA). The first is a non-parametric method; it does not require a specific functional hypothesis on how inputs are transformed into outputs and can be applied in a setting of multiple outputs. The second is a parametric method based on a production function estimated through the model. In both cases, the production unit is an organizational structure and autonomous decision-making unit (DMU). DMUs should be uniform (all use the same types of resources to produce the same types of results), independent (one unit must not, in any way, affect the performance of another) and autonomous (each unit must have the ability to decide how to use its resources to produce results). ${ }^{3}$

DEA is a deterministic method; it is sensitive to sampling variation and to measurement errors and outliers. It also requires a second stage procedure to analyze efficiency determinants. ${ }^{4}$ The statistical foundation of the second stage approach is subject to intensive debate due to the bias and serial correlation of the DEA efficiency scores. To address this problem, several authors propose the use of a bootstrap method to correct for the small sample bias and serial correlation of the DEA efficiency estimates (Simar and Wilson 1998, 2000).

Despite its drawbacks, given the multiple outputs and inputs in education and the lack of specific assumptions on the function relating outputs to inputs, DEA is better suited for the estimation of school efficiency than its parametric counterparts. ${ }^{5}$ Moreover, the efficiency frontier drawn by DEA is composed by the most efficient observed units and their linear combinations, allowing for the identification of best practices to provide guidance to less efficient schools. Indeed, benchmarking exercises can be carried out easily by analyzing distances of each school from the frontier. The idea is that if a school can produce a certain level of output utilizing specific input levels, another school of equal scale should be capable of doing the same. The most efficient schools form a virtual combination of schools, allowing the computation of an efficient solution for every level of input or output. The analysis performed in this article is based on two large samples of public schools: one for primary education and one

\footnotetext{
3 In Italy schools can be considered real DMU only since the mid-nineties, when they were assigned administrative, organizational, and educational autonomy and started managing a proper budget. Indeed, although they cannot entirely control the amount of input, schools have some room in managing resources, in providing incentives to staff and even more in the organization of service and education initiatives through which they can influence student performance.

4 The DEA method refers to the work of Farrell efficiency measures on (1957) later expanded and made operational by Charnes et al. (1978), using linear programming algorithms. The only restrictions on the characteristics of the production system is convexity and free disposal (possibility of destroying inputs without costs). DEA estimates a non-parametric efficiency frontier that involves all the DMUs. The reconstruction of the frontier also allows to evaluate the inefficiency of the other DMUs on the basis of the minimum distance from the frontier itself.
}

5 DEA's only assumption is convexity of the underlying set of feasible input-output combinations. 
for lower secondary education (both containing specialized as well as comprehensive schools), with reference to the school year 2009-2010. The samples are those built by INVALSI for the national student assessment and the student cognitive tests are administered by external observers in order to avoid cheating or student skimming. ${ }^{6}$ These are statistical samples, with regional significance, drawn according to a twostage procedure: first the schools and then one or two entire classes of students in each school.

Average INVALSI test scores for each school were combined with other sources of information. Namely, the Ministry of Education provided administrative data on personnel and school service characteristics, detailed data on revenue and expenditure come from school budgets, and statistical variables related the school's geographical location are from the national statistical institute (ISTAT). We managed to merge data from all sources of interest for 1,098 schools in primary education (against 1,385 from the original sample) and 1,061 schools in lower secondary education (against 1,309 from the original sample). ${ }^{7}$

In addition to school spending (net of salaries) per student, the number of teachers per student and the number of other staff per student, our input variables include a characterization of the school's catchment area in terms of average socio-economic and cultural background of its students. Indeed, results in terms of student learning outcomes are highly related to cognitive abilities and skills gained by students in previous years and the socio-economic conditions of their families and peers (e.g., Brunello and Checchi 2006; Schütz et al. 2005; Woessmann 2003; Hanushek 2002). Since Italian public schools cannot select their students, the choice of including the social and economic background among inputs in the model is questionable. However, given its relevance, it has been considered to account for its major effect on the outputs, as done by several authors (Oliveira and Santos 2005; Tyagi et al. 2008, Aaltonen et al. 2006; Portela and Camanho 2007). The use of an all-in-one approach DEA estimation-including both discretionary and non-discretionary variables for DMUs - is customary when the latter are continuous and internal to the production process. By using an output-oriented model as in our case (see paragraph 3), all inputs are implicitly treated as non-discretionary anyway (Fried et al. 2008).

Among the inputs of our model, data on spending per student represents the total payments of the school budget on the total number of students served: roughly this corresponds to the schools' running costs per capita and does not include staff salaries. Schools spend directly for ordinary bills and consumption of goods and services, extra-curricular educational projects, short-term substitute teachers, extra subsidiary payments for their staff, while salaries are paid by the central government and for this reason they are not included in the school budget.

\footnotetext{
6 The participation of schools in INVALSI education assessments was voluntary for several years, but starting from school year 2009-2010 it is done on a census basis (all schools, public and private) and all students in class. The administration of the testing is done directly by the schools at a pre-fixed date and following information provided by INVALSI. However, a regionally representative sample of schools is drawn every year, for faster and un-biased results to be made available. External observers are sent to the sample schools.

7 The loss of observations is negligible and it does not cause an appreciable distortion in the statistical representativeness of the sample.
} 
Data on students and teaching staff refer either to the primary or to the lower secondary grades. Even in the case of comprehensive schools, the number of teachers 8 per pupil is calculated-separately for each educational level (i.e., only for the primary grades or only for lower secondary grades, depending on which sample is being analyzed). On the other hand, administrative, technical and auxiliary staff is associated with the school in its entirety, regardless of the grades, and it is compared to the total number of pupils.

The average socio-economic status and cultural (ESCS) index is calculated by INVALSI on the basis of a student questionnaire. ${ }^{9}$ This variable depends on the context and is largely influenced by location (on which the school can hardly, at least in the medium term, act). The index summarizes the answers given by students regarding the employment status of parents and their educational level, and the presence of some material goods at home: for example, the availability of a quiet place to study, a desk for homework, books, encyclopedias on paper or in digital form, an Internet connection, a single bedroom, the number of bathrooms, a car, etc. At the national level, the index is normalized to a scale with mean equal to 0 and standard deviation equal to 1 (Campodifiori et al. 2010).

Input values are shown in Table 1, for the whole sample (ITALY) and for macroregional breakdowns. ${ }^{10}$ The average level of expenditure is approximately 740 euros per capita in primary schools and about 640 euros in lower secondary. Average per capita expenditure tends to be greater in the South and the Centre than in the North, especially in primary education. In some areas of the South, for the period under consideration, this is the effect of a relevant additional contribution to school budgets from projects financed by the European Union structural funds. ${ }^{11}$ In primary education there are about 10 teachers per 100 students, with slightly greater values in the North and lower values in the South; in lower secondary education the average teacher to student ratio amounted to 10.8 , with greater values in the South, where variability is also larger. Finally, the other staff to student ratios presents even larger variations within each macro-area: the average is just over 3 personnel units for 100 students, but the range in our sample displays from a minimum of about 1.5 to a maximum of over 10 .

\footnotetext{
8 Teachers holding religion classes are excluded from the analysis.

9 It is similar to the OECD-PISA ESCS indicator.
}

10 The North, Centre and South macro-regional breakdown is the one used in official statistics. More precisely North includes: Piedmont, Liguria, Lombardy, Veneto, Friuli Venezia-Giulia , Emilia Romagna; Centre includes: Tuscany, Umbria, Marche, Lazio, and South includes: Abruzzo, Molise, Campania, Apulia, Basilicata, Calabria and Sicily. Data for Valle d'Aosta and Trentino Alto Adige are not reported as these autonomous Regions fund public schools directly.

11 Indeed, the 2007-2013 EU structural funds programming cycle direct a conspicuous amount of resources to schools in four regions of Southern Italy (referring to our sample, the peak is in Calabria with about 100 euro per student, followed by Sicily with about 56 euro per student) with the aim of narrowing the disparities in students and schools' performance, and enhancing the quality of human capital in the more depressed areas of the country. The amount of EU funding spent from the school's budget is not available in our dataset. The only proxy for this is the amount of EU financial support actually received in the same year. The main limit of this variable is that part of the EU funds may be used to finance capital expenditure; therefore, the simultaneous deletion in the empirical model of capital expenditure and revenue from the EU can bring, at least for some schools, to an under-estimation of current expenditure. 
Table 1 Input variables

\begin{tabular}{|c|c|c|c|c|c|c|c|c|}
\hline \multirow[t]{2}{*}{ Variables } & \multicolumn{2}{|l|}{ North } & \multicolumn{2}{|l|}{ Centre } & \multicolumn{2}{|l|}{ South } & \multicolumn{2}{|l|}{ ITALY } \\
\hline & Mean & $\mathrm{CV}$ & Mean & $\mathrm{CV}$ & Mean & $\mathrm{CV}$ & Mean & $\mathrm{CV}$ \\
\hline \multicolumn{9}{|l|}{ Primary education } \\
\hline $\begin{array}{l}\text { School } \\
\text { expenditure (net } \\
\text { of salaries) per } \\
\text { student (euro) }\end{array}$ & 616.8 & 0.45 & 754.6 & 0.47 & 837.9 & 0.45 & 741.5 & 0.48 \\
\hline $\begin{array}{l}\text { Teachers per } \\
\text { student }(\%)\end{array}$ & 10.33 & 0.14 & 10.05 & 0.15 & 9.74 & 0.22 & 10.01 & 0.20 \\
\hline $\begin{array}{l}\text { Other staff per } \\
\text { student }(\%)\end{array}$ & 3.44 & 0.26 & 3.54 & 0.27 & 3.70 & 0.30 & 3.60 & 0.30 \\
\hline ESCS (5th grade) & -0.02 & -19.23 & 0.08 & 5.35 & -0.19 & -2.59 & -0.07 & -6.86 \\
\hline \multicolumn{9}{|c|}{ Lower secondary education } \\
\hline $\begin{array}{l}\text { School } \\
\text { expenditure (net } \\
\text { of salaries) per } \\
\text { student (euro) }\end{array}$ & 565.1 & 0.37 & 591.1 & 0.45 & 722.4 & 0.50 & 639.1 & 0.48 \\
\hline $\begin{array}{l}\text { Teachers per } \\
\text { student }(\%)\end{array}$ & 10.47 & 0.18 & 10.17 & 0.23 & 11.35 & 0.31 & 10.8 & 0.26 \\
\hline $\begin{array}{c}\text { Other staff per } \\
\text { student }(\%)\end{array}$ & 3.04 & 0.28 & 3.02 & 0.31 & 3.27 & 0.38 & 3.1 & 0.34 \\
\hline ESCS & 0.02 & 24.77 & 0.10 & 3.96 & -0.18 & -2.97 & -0.05 & -10.12 \\
\hline
\end{tabular}

Values of the average ESCS index are in line with expectations, with Southern regions presenting a higher concentration of disadvantaged backgrounds. It is worth to note that the coefficient of variation is large in all areas but it presents a considerably greater variability in the North. There is no sign of significant correlation between input variables and, in particular, between school expenditure (net of salaries) per student and average ESCS, even within separate macro-regions. ${ }^{12}$

We consider two output variables: the INVALSI average school performance scores in math and Italian (reading). The average score provides the level of performance of respondents accounting for the difficulty of each test item by applying Rasch methods. By convention, the score is normalized to a scale with mean 500 and standard deviation 100.

In primary classes, the national assessment is conducted in grade 2 and 5 . In this case, in order to have a summary indicator for the primary level, we built two weighted indicators, one for math scores and one for reading scores, with weights equal to the actual number of participants to the tests in each grade. For lower secondary classes, the national assessment is conducted in grade 6 and we consider the scores for both the math and the reading performance separately. Average student performance typically suffers the traditional Italian North-South divide, whereby schools in the North display higher scores than those in Central and Southern regions (Table 2).

\footnotetext{
12 Considering the three macro-regions separately, correlation between school expenditure per student and ESCS ranges between -0.07 and 0.25 .
} 
Table 2 Output variables

\begin{tabular}{|c|c|c|c|c|c|c|c|c|}
\hline \multirow[t]{2}{*}{ Variables } & \multicolumn{2}{|l|}{ North } & \multicolumn{2}{|l|}{ Centre } & \multicolumn{2}{|l|}{ South } & \multicolumn{2}{|l|}{ Italy } \\
\hline & Mean & $\mathrm{CV}$ & Mean & $\mathrm{CV}$ & Mean & $\mathrm{CV}$ & Mean & $\mathrm{CV}$ \\
\hline \multicolumn{9}{|l|}{ Primary education } \\
\hline $\begin{array}{l}\text { Average math } \\
\text { performance } \\
\text { (weighted 2nd and } \\
\text { 5th grade) }\end{array}$ & 501.12 & 0.06 & 497.48 & 0.08 & 496.18 & 0.13 & 498.22 & 0.10 \\
\hline $\begin{array}{l}\text { Average reading } \\
\text { performance } \\
\text { (weighted 2nd and } \\
5 \text { th grade) } \\
\text { Lower secondary edu }\end{array}$ & 505.70 & 0.05 & 502.76 & 0.07 & 489.15 & 0.10 & 498.08 & 0.08 \\
\hline $\begin{array}{l}\text { Average math } \\
\text { performance (6th } \\
\text { grade) }\end{array}$ & 513.81 & 0.06 & 507.91 & 0.06 & 476.99 & 0.10 & 496.98 & 0.09 \\
\hline $\begin{array}{l}\text { Average reading } \\
\text { performance (6th } \\
\text { grade) }\end{array}$ & 511.32 & 0.06 & 509.01 & 0.06 & 476.24 & 0.09 & 496.02 & 0.08 \\
\hline
\end{tabular}
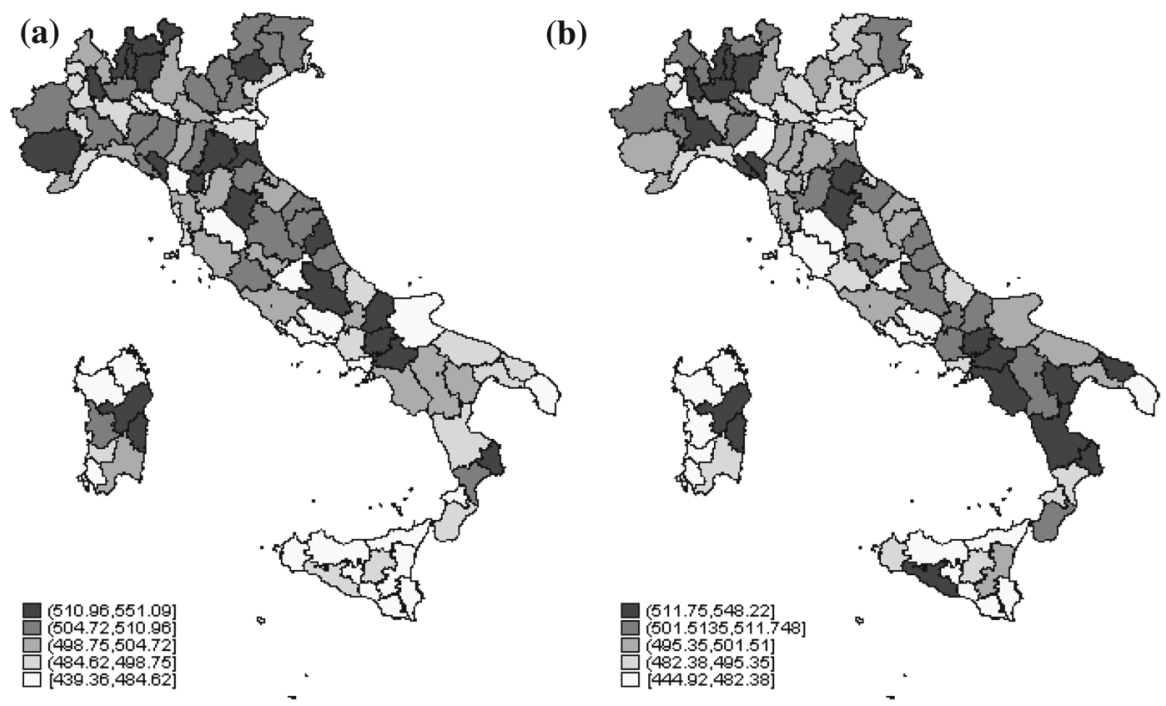

Fig. 1 Outputs for primary education: INVALSI scores (a) reading (b) math

The provincial-level maps in Figs. 1 and 2 show an even more complex situation. School scores above the national average are also achieved in several areas of the South, particularly as regards math scores in primary grades. There is a considerable variability of outputs both as concerns reading and math, and within-area variability is more pronounced than between-area variability. In fact, in all macro-areas, the difference between the worse and best performing province is roughly 100 score points, considered to be equivalent to approximately two years of education. In lower 

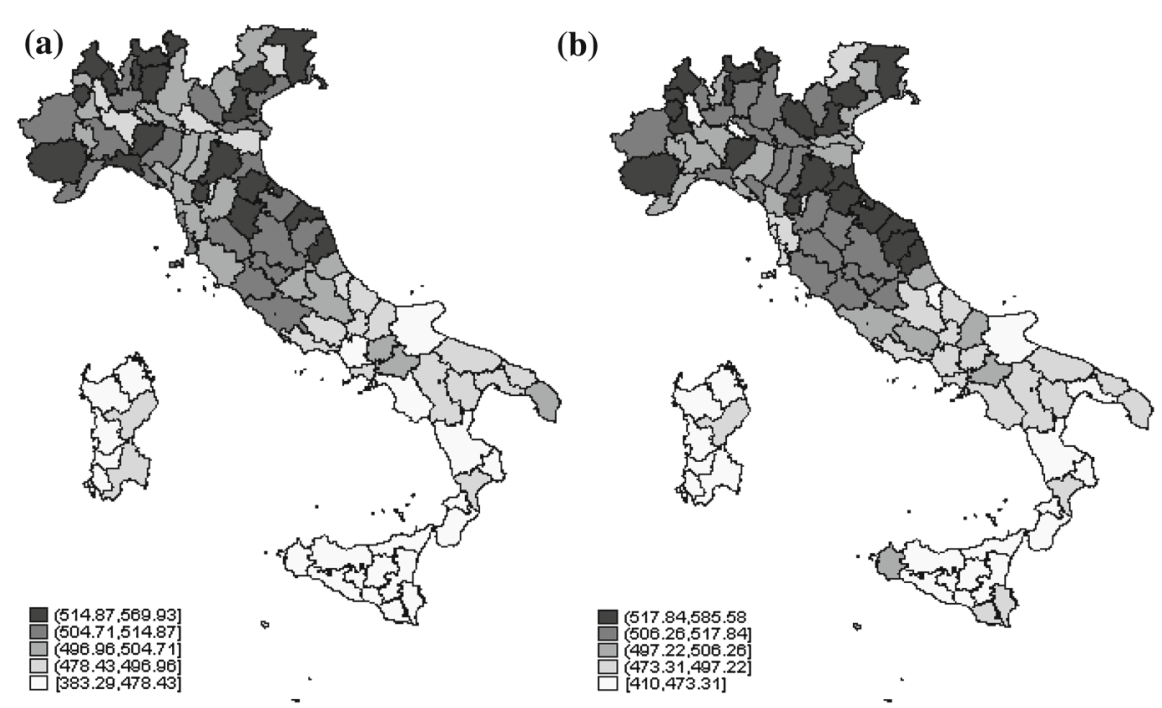

Fig. 2 Outputs for lower secondary education: INVALSI scores (a) reading (b) math

secondary grades, however, the score of the worse performing province in the South is way lower than its equivalent in the North (383 against 484 as concerns reading and 410 against 471 as concerns math). Heterogeneity characterizes mostly the South, which displays a standard deviation generally $>20$ for both math and reading scoresa difference close to half a year of education. Average performance in math is usually more variable than performance in reading (see "Appendix", Tables 8, 9).

Within-area variability of inputs tends to be remarkable as well, and even greater than the within-area variability of output variables. Again the differences are stronger among Southern provinces than among provinces in the other macro-areas. The provincial distribution of teachers per student tends to be more concentrated towards lower values, with a longer tail to reach the maximum value and a greater range in the South. The same holds for the ratio between other staff and students, although maximum values are less distant from the third quartile. School expenditure (net of salaries per student) is generally skewed towards lower values and differences between the last 25 per cent of provinces are greater than between the first 25 per cent, especially in the Center and South. Finally, within-area variability is greatest when it comes to the ESCS index. Despite the fact that in this case Northern provinces display a wider range (from -0.74 to 0.30 in primary education and from -0.35 to 0.56 in secondary education), the Southern provinces still dominate the others in terms of variability.

\section{Results and discussion}

As mentioned, in our specification the output variables are student performance measures based on school average INVALSI math and reading scores. The inputs are resources used by each school, proxied by four variables: teacher-student ratio, other school personnel-student ratio, school expenditure per student and the average socio- 
economic status of students (average ESCS). The analysis was carried out separately for the primary and lower secondary education segments. ${ }^{13}$

The DEA models can be estimated by adopting two different approaches, both based on the concept of technical efficiency, i.e. the ability of the DMU, given the current technology, to produce the maximum output level from a given combination of input (output-oriented model), or alternatively to use the least possible amount of input to obtain a given output (input-oriented model). Our models are output oriented, given that schools have a higher control on output than on input. Indeed, human and financial resource allocation is determined by the central government decisions and the socio-economic and cultural background of students is often a consequence of the school's location. Nevertheless, schools have indirect control over these variables. First of all, through decisions on class making, affecting size (and therefore the number of teachers per pupil) but also on the way students are grouped (possibly to take into account different levels of social or educational difficulties). Schools also decide whether to implement special education projects, schedules, and all matters affecting the management of day-to-day service. Although principals do not choose teachers and only marginally decide their salary levels, school coordination activities can influence the degree of cooperation among personnel and with families, and can support the choice of the "best" educational projects.

\subsection{Primary and lower secondary school efficiency and potential improvements}

The results shown in this paper refer to bias-corrected DEA scores obtained after running 200 bootstrap replicates. For the sake of simplicity, scores are normalized to a scale between 0 (minimum efficiency) and 1 (maximum efficiency). ${ }^{14}$ School efficiency scores were calculated by assuming variable returns to scale of the production factors (VRS). From an interpretation perspective, given that quality of inputs is not directly taken into account in the model, variable returns to scale seem preferable. To support this intuition, we also carried out the Bogetoft and Lars statistical test (Bogetoft and Otto 2011). ${ }^{15}$

Strong variability of the main input variables raises the question of whether the production context is sufficiently homogenous to consider a unique efficiency frontier

\footnotetext{
13 All DEA estimates were obtained using the free software R (http://www.r-project.org/).

14 Spearman's and Kendall's correlation coefficients both clearly show that there is a high correlation between the original efficiency scores and the bias-corrected efficiency scores, confirming the high stability of school ranking which is always $>0.9$.

15 This procedure is based on the idea that constant returns to scale are valid if one assumes that all DMUs operate at optimal scale. The null hypothesis is CRS and the test statistic is calculated as the ratio between the average efficiency scores obtained in the case of constant returns to scale (numerator) and in a model with variable returns (denominator), both estimated in our case through the extraction of 200 replica. The null hypothesis of constant returns to scale was rejected in the case of both primary schools and lower secondary schools. For the sake of simplicity we report on the results obtained at the national level: in the case of primary schools, the critical relationship (with $\alpha=10 \%$ ) is equal to 0.836 and is greater than the test statistic (S) carried out on the sample, which results to be equal to 0.828 . In the case of lower secondary schools, the null hypothesis is rejected with a critical ratio equal to 0.772 compared with a test statistic equal to 0.754 .
} 
Table 3 DEA bias corrected efficiency scores for North, Centre and South

\begin{tabular}{|c|c|c|c|c|c|c|c|c|c|c|c|c|}
\hline \multirow[t]{2}{*}{ Variables } & \multicolumn{2}{|l|}{ North } & \multirow[b]{2}{*}{ Min } & \multirow[b]{2}{*}{ Max } & \multicolumn{2}{|l|}{ Centre } & \multirow[b]{2}{*}{ Min } & \multirow[b]{2}{*}{$\operatorname{Max}$} & \multicolumn{2}{|l|}{ South } & \multirow[b]{2}{*}{ Min } & \multirow[b]{2}{*}{ Max } \\
\hline & Mean & $\mathrm{CV}$ & & & Mean & $\mathrm{CV}$ & & & Mean & $\mathrm{CV}$ & & \\
\hline \multicolumn{13}{|l|}{ Primary education } \\
\hline $\begin{array}{l}\text { Efficiency scores bias } \\
\text { corrected }\end{array}$ & 0.88 & 0.05 & 0.72 & 0.99 & 0.85 & 0.06 & 0.65 & 0.96 & 0.74 & 0.10 & 0.25 & 0.98 \\
\hline \multicolumn{13}{|c|}{ Lower secondary education } \\
\hline $\begin{array}{l}\text { Efficiency scores bias } \\
\text { corrected }\end{array}$ & 0.91 & 0.05 & 0.71 & 0.99 & 0.91 & 0.05 & 0.79 & 0.99 & 0.79 & 0.09 & 0.45 & 0.96 \\
\hline
\end{tabular}

(a) North

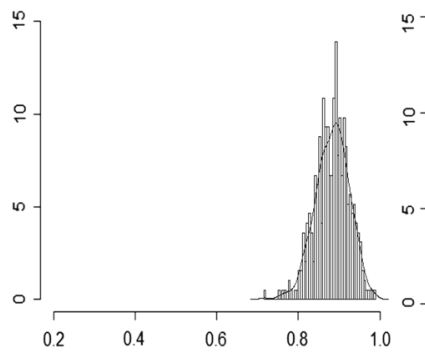

(b) Centre

(c) South

Fig. 3 Primary education: histogram of the bias-corrected efficiency scores Variable Returns to scale (VRS) for North, Centre and South Italy

(a) North

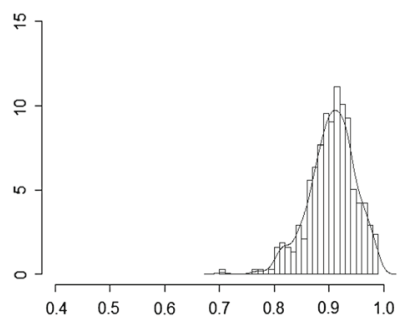

(b) Centre

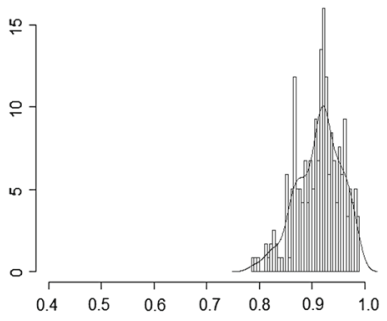

(c) South

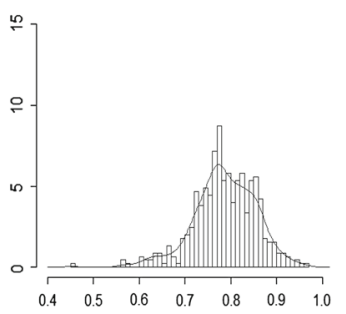

Fig. 4 Lower secondary education: histogram of the bias-corrected efficiency scores Variable Returns to scale (VRS) for North, Centre and South Italy

for all Italian schools. Descriptive statistics in Table 1 suggest the presence of three distinct groups along the North, Central, South axis. There also are some differences in the institutional context: European structural funds are a major additional revenue opportunity only for schools in the South. Therefore, DEA estimates were calculated for separate subsets of schools belonging to the same macro-region.

The resulting VRS bias-corrected efficiency scores are provided in Table 3 and Figs. 3, 4. They are on average high both in primary and lower secondary education and in all macro-regions. However, there are significant differences in the degree of efficiency at individual school level. 
Table 4 Wilcoxon-Mann-Whitney signed-rank test between national and macro-region efficiency distributions

\begin{tabular}{lccc}
\hline & North vs. Italy & Centre vs. Italy & South vs. Italy \\
\hline Primary education & & & \\
$Z$ & -16.33 & 12.63 & 10.36 \\
Prob $>|z|$ & 0.00 & 0.00 & 0.00 \\
Lower secondary education & & & \\
$Z$ & 16.91 & -1.41 & -11.91 \\
Prob $>|z|$ & 0.00 & 0.16 & 0.00 \\
\hline
\end{tabular}

North and Center regions present a greater concentration of more efficient schools and smaller variability, while Southern schools display a lower average efficiency. In fact, average efficiency scores for this macro-area are similar to those of the least efficient schools in the North and Centre and the whole distribution has a longer left-hand tail.

In order to verify the intuition that there are different frontiers, we checked whether the three groups of territorially defined schools come from a common efficiency distribution or not. Basically, the efficiency scores from the three DEA models were compared to the results of a DEA model on the overall national sample with the Wilcoxon-Mann-Whitney signed-rank test. The test dismissed the null hypothesis of single macro-regions and the overall sample belonging to the same population, with the sole exception of the efficiency scores related to the Centre lower secondary schools (Table 4).

This result suggests that it may be more appropriate to carry out benchmarking exercises for schools within their own geographical area.

In order to measure the potential improvements, outputs of inefficient DMUs were expanded proportionally by multiplying the efficiency score times the output. ${ }^{16}$ By summing these "slack" values we obtain a measure of the average potential improvement, given the observed inputs. Data in Table 5 indicate there are, in general, greater (absolute and relative) margins of improvement in primary schools than in lower secondary schools across all macro-areas. However, the potential rate of improvement in the South is more than twice the one in the other areas: given the current level of available resources, if all schools would perform like the most efficient ones, the gain in efficiency would be around 36 percent for primary schools and 28 percent for lower secondary schools (against values of at most 18 and 11 percent in the Centre and North).

Finally, to check the robustness of our reference model (based on four inputs), we estimated a second model based on three inputs, i.e. excluding the average ESCS. There are no dramatic changes in the efficiency patterns. Kendall rank correlation between the efficiency scores of the reference model and second model is over 0.86 in

16 In an output-oriented technical efficiency model, schools are deemed to be efficient if $\theta=1$, and inefficient if $\theta>1$. For presentation purposes in this paper efficiency scores have been normalized on a scale from 0 to 1 . However, in the estimation of potential productivity gains, the original scores are used. 
Table 5 Potential improvement of school productivity on the output side

\begin{tabular}{lllcr}
\hline & Output 1 & Output 2 & Total slack & $\begin{array}{r}\text { Potential } \\
\text { improvement } \\
(\%)\end{array}$ \\
\hline North primary schools & 501.12 & 505.70 & 133.47 & 13.50 \\
Centre primary schools & 497.48 & 502.76 & 174.43 & 17.72 \\
South primary schools & 496.18 & 489.15 & 341.13 & 36.06 \\
North lower secondary schools & 513.81 & 511.32 & 107.29 & 10.75 \\
Centre lower secondary schools & 507.91 & 509.01 & 96.31 & 9.72 \\
South lower secondary schools & 476.99 & 476.24 & 260.48 & 28.19 \\
\hline
\end{tabular}

both primary and lower secondary education. This result hints to the fact that, despite ESCS being a strong indicator for the context around the school, efficiency may be influenced by other contextual factors that are not considered in our reference model and should be identified in the second-stage analysis.

\subsection{Determinants of school efficiency}

Having ranked schools according to their efficiency scores, we are interested in investigating whether there are factors related to their organizational structure or to the external context, which play a role in making one school more efficient than another. In particular, we consider the following aspects:

- features related to the management capacity of schools in terms of revenue sources, the composition of expenditure and financial balance;

- organizational characteristics, such as "specialized" versus "comprehensive" schools, the number of service delivery points (e.g., the same school can have different buildings in different areas of the same town or, sometimes, in different municipalities when they serve smaller and remote areas), but also the presence of tenured staff, of full-time students (staying for programs in the afternoon after compulsory classes are held), of teachers assisting students with special educational needs (SEN) and class size;

- territorial characteristics that may influence the ability to exploit economies of scale, such as the remoteness and degree of urbanization;

- features reflecting the economic status and social cohesion of the area in which the school is located.

Descriptive statistics for the explanatory variables are reported in "Appendix" (Tables $10,11)$.

A major financial issue characterizing Italian public schools is the large amount of revenue arrears claimed from the central government. Revenue arrears have accumulated over time and often date several years ago. At the same time, a significant share of schools is in financial trouble because their end-of-year accounts display an amount of cash which is lower than their obligations. In 2010 the percentage of schools with 
liquidity unable to cover annual commitments was about 33 per cent in the Centre, 21 per cent in the North and 38 per cent in the South. In other words, although there is no sign of the arrears being refundable, schools might be inflating the budget on which they plan their annual activities, even when they end up not being able to pay for them.

In order to explore these issues more in depth, a second stage analysis was conducted to identify determinants of efficiency for primary and lower secondary education by adopting a Tobit model, ${ }^{17}$ with standard error corrected for heteroscedasticity using the White procedure, as follows:

$$
\mathrm{EFF}_{\mathrm{i}}=\mathrm{f}\left(\mathrm{Z}_{\mathrm{i}}, \beta\right)+\mathrm{u}_{\mathrm{i}}
$$

The observable dependent variable $\left(\mathrm{EFF}_{S}\right)$ is given by the bias-corrected efficiency scores, assuming variable returns to scale. ${ }^{18}$ The possible determinants of efficiency $(Z)$ include context variables related to school location, ${ }^{19}$ financial variables concerning the school budget, ${ }^{20}$ variables concerning the structural and organization characteristics of schools. ${ }^{21}$

Results are presented in Tables 6 and 7, separately for primary and lower secondary education, and for the three different macro-regions. For both levels of education, our findings show distinct efficiency determinants for each macro-area. The main common factor refers to critical financial issues, which do not seem to carry any explanation for efficiency: in all three macro-regions and for both levels of education, the level or persistence of revenue arrears and the ability to meet spending commitments with available liquidity do not have a significant impact on the degree of efficiency.

Starting with primary education, one can note that among all variables taken in the model, factors such as the family and private sector financial contributions to the schools, the percentage of revenue arrears from previous years and the number of service delivery points of the school do not seem to have any relation with the degree of efficiency.

\footnotetext{
17 Second-level analyses of DEA models commonly use a Tobit regression to analyse the relationship between the efficiency scores and potential exogenous determinants, although there is an extensive debate on whether it is advisable and beneficial compared to an OLS model to model DEA scores (Hoff 2007). In this analysis, we present the Tobit results; the resulting conclusions do not differ from the results of an OLS model.

18 Efficiency scores were normalized to a 1-100 scale, in order to make Tobit results more readable.

19 Some of the geographical variables initially considered were excluded from the final specification of the model, as they do not seem to play a major role on the levels of school efficiency. Specifically, several variables were tested regarding: (a) possible proxies of urbanization such as population size of the municipality where school is located, urban density and total population; (b) Social capital of the province in which the school is located by using Cartocci's indicator (2007); (c) the altimetry of municipalities where school is located; (d) regional or provincial dummy variables.

20 The variables concerning the composition of school revenues (e.g., central / local government, EU, other) were excluded from the final model because they were considered not statistically significant.

21 Some structural variables, such as the percentage of administrative staff and the age of teachers and principal, were excluded from the analysis because they were not statistically significant.
} 
Table 6 Tobit estimates of efficiency factors for North, Centre and South Italy-primary education

\begin{tabular}{|c|c|c|c|c|c|c|}
\hline \multirow[t]{2}{*}{ Variables } & \multicolumn{2}{|l|}{ North } & \multicolumn{2}{|l|}{ Centre } & \multicolumn{2}{|l|}{ South } \\
\hline & Coeff. & SD & Coeff. & SD & Coeff. & SD \\
\hline Perc. full-time pupils & 0.216 & 0.674 & -3.797 & $1.276 * * *$ & -0.108 & 1.225 \\
\hline Perc. tenured teachers & 5.928 & $3.094 *$ & 2.697 & 5.223 & 5.294 & 6.043 \\
\hline $\begin{array}{l}\text { Comprehensive } \\
\text { school }\end{array}$ & -0.180 & 0.584 & -0.891 & 0.874 & -2.724 & $0.857 * * *$ \\
\hline Class size & 0.115 & 0.117 & 0.536 & $0.161 * * *$ & -0.133 & 0.146 \\
\hline $\begin{array}{l}\text { Family and private } \\
\text { sector contributions }\end{array}$ & 0.001 & 0.007 & 0.005 & 0.004 & 0.007 & 0.008 \\
\hline $\begin{array}{l}\text { Perc. revenue arrears } \\
\text { prev. years }\end{array}$ & -0.378 & 0.513 & 0.385 & 0.998 & -1.154 & 1.020 \\
\hline $\begin{array}{l}\text { Perc. capital } \\
\text { investment }\end{array}$ & 22.258 & $6.249 * * *$ & -3.956 & 20.487 & 10.561 & 14.287 \\
\hline Female employment & 0.253 & 0.075 & 0.315 & $0.120 * * *$ & 0.296 & $0.074 * * *$ \\
\hline Perc. SEN teachers & -1.089 & 5.937 & -16.097 & $8.249^{*}$ & -5.015 & 7.167 \\
\hline Perc. immigrants & -11.409 & $2.130 * * *$ & -9.865 & $4.754 * *$ & -10.802 & 8.785 \\
\hline $\begin{array}{l}\text { No of service delivery } \\
\text { points }\end{array}$ & 0.043 & 0.175 & -0.214 & 0.246 & 0.083 & 0.243 \\
\hline Constant & 72.072 & $5.574 * * *$ & 64.917 & $8.166^{* * * *}$ & 65.822 & $7.445 * * *$ \\
\hline Observ. no. & 388 & & 249 & & 461 & \\
\hline $\mathrm{F}$ & 4.920 & & 4.010 & & 3.620 & \\
\hline Prob $>\chi^{2}$ & 0 & & 0 & & & 0 \\
\hline
\end{tabular}

Notes: * Significant at $10 \%, * *$ significant at $5 \%, * * *$ significant at $1 \%$

In Northern regions, the percentage of tenured teachers and of capital investment are both positively related to efficiency. Since mobility of tenured teachers is reduced respect to annually-contracted ones, this result hints to the fact that it may be more efficient for a school to keep the same teachers from one year to the other, reducing the need for integration and coordination. The greater experience and stability of the staff and greater familiarity between teachers, students, and their families may also provide benefits. Moreover, a investment is a typical proxy of the "quality" of expenditure, so its positive effect is not surprising. Conversely, being all other variables equal, the percentage of immigrants has a negative effect on efficiency. This raises the issue of the importance of caring for the increasing share of non-nationals in the student body in the more economically developed part of the country.

When it comes to primary schools in the Centre, the larger the number of students, the more efficient the schools are, representing the benefits of scale economies. Female employment also stands out as a major (positive) element for efficiency. Its role could be related to the more favorable economic context characterizing areas with more female employment, but also to the greater motivation working mothers might have for better educational performance of their children. Although they might have less time to check on homework or school activities, they might have greater esteem for teacher's instructions (often working women like them) and more awareness of the fact that early age education counts for future job opportunities. This factor is partially 
Table 7 Tobit estimates of efficiency factors for North, Centre and South Italy-lower secondary education

\begin{tabular}{|c|c|c|c|c|c|c|}
\hline \multirow[t]{2}{*}{ Variables } & \multicolumn{2}{|l|}{ North } & \multicolumn{2}{|l|}{ Centre } & \multicolumn{2}{|l|}{ South } \\
\hline & Coeff. & SD & Coeff. & SD & Coeff. & SD \\
\hline Perc. full-time pupils & 1.62 & 1.08 & 6.30 & $2.26^{* * *}$ & 0.18 & 1.69 \\
\hline Perc. tenured teachers & 6.56 & $2.11 * * *$ & 2.50 & 2.81 & 7.67 & $3.22 * * *$ \\
\hline $\begin{array}{l}\text { Comprehensive } \\
\text { school }\end{array}$ & -0.92 & 0.65 & -0.47 & 0.84 & 0.37 & 0.92 \\
\hline Class size & 0.22 & 0.13 & 0.25 & $0.14 *$ & 0.05 & 0.14 \\
\hline $\begin{array}{l}\text { Family and private } \\
\text { sector contributions }\end{array}$ & 0.01 & $0.00 * *$ & -0.01 & $0.00 *$ & 0.01 & 0.01 \\
\hline $\begin{array}{l}\text { Perc. revenue arrears } \\
\text { prev. years }\end{array}$ & -0.64 & 0.55 & 0.52 & 0.89 & -0.87 & 1.05 \\
\hline $\begin{array}{l}\text { Perc. capital } \\
\text { investment }\end{array}$ & -2.02 & 12.35 & 10.97 & 11.72 & 10.57 & 7.32 \\
\hline Female employment & 0.14 & $0.08 *$ & 0.21 & $0.09 * *$ & 0.37 & $0.07 * * *$ \\
\hline Perc. SEN teachers & -6.03 & 5.46 & 3.41 & 6.71 & -6.23 & 6.00 \\
\hline Perc. of immigrants & -13.23 & $1.75 * * *$ & -13.44 & $3.06^{* * *}$ & -5.26 & 9.67 \\
\hline $\begin{array}{l}\text { No of service delivery } \\
\text { points }\end{array}$ & 0.18 & 0.17 & 0.28 & 0.26 & 0.15 & 0.28 \\
\hline Constant & 77.04 & $4.20 * * *$ & 76.53 & $4.79 * * *$ & 61.13 & $4.84 * * *$ \\
\hline Observ. No. & 373 & & 231 & & 439 & \\
\hline $\mathrm{F}$ & 11.67 & & 4.11 & & 3.96 & \\
\hline Prob $>\chi^{2}$ & 0 & & 0 & & 0 & \\
\hline
\end{tabular}

Notes: * Significant at $10 \%, * *$ significant at $5 \%, * * *$ significant at $1 \%$

counterbalanced by the negative effect of the percentage of full time pupils (which is usually positively related to female employment, since working mothers keep their children in school in the afternoon). Longer school hours for these students apparently result into higher costs which are not offset by greater student performance, thus yielding a negative effect on efficiency. Finally, the share of teachers assisting students with special needs (SEN) is marginally significant, with a negative impact on efficiency.

Focusing on schools in the South, we identify only two statistically significant variables and of opposite sign. Once again, female employment has a positive effect on school efficiency. But, as concerns management issues, comprehensive schools (i.e., schools where both primary and lower secondary education are delivered) present an unexpected negative impact. In other words, in Southern Italy, comprehensive schools seem to be less efficient than schools that specialize in one or the other education segment. This may be worth of special attention in the view of recent Italian legislation which requires the fusion of all primary and lower secondary schools into comprehensive schools. The underlying idea is to improve learning conditions in the transition between the two education levels and to rationalize expenditure by exploiting scale economies as school size increases. This action is more recent in Southern regions than in Northern ones.

One could suppose comprehensive schools to be characterized by a greater number of service delivery points than other schools - thereby affecting school costs. It turns 
out that this variable is not necessarily associated to a more fragmented organization, especially in the South (see "Appendix" Tables 12 and 13). ${ }^{22}$ Therefore, comprehensive schools carry some other relevant characteristic, possibly more intrinsic, which affects efficiency. They need to adjust to the presence of teachers trained for different education purposes and to tackle with younger and older students featuring different needs. They are usually directed by a principal carrying a specific background experience in only one of the two education segments. Being this factor significant only in Southern schools, it might depend on the more recent presence of comprehensive schools in this area and could be a short-term effect.

The efficiency in lower secondary education does not seem affected by the share of teachers assisting students with special educational needs (SEN) and the number of service delivery points of the school, just like in primary education. However, family and private sector financial contributions play a role in the North and Center and the negative effect of comprehensive schools in the South disappears here. Finally, in all macro-areas, the economic and social benefits of the context related to greater shares of female employment is always positive and significant on school efficiency.

The share of students with an immigrant background continues to play a negative role on efficiency in the North and, again, the percentage of tenured teachers is positively related to efficiency. Other factors associated to greater efficiency are the volume of family and private sector financial contributions (pointing out to the potential benefits of direct participation and involvement of the local environment to the school's mission) and class size (with its scale economies).

These variables are all significant and in the same direction also when examining the schools in Central Italy. The only exception concerns private contributions, which present a negative coefficient here, although of low magnitude and only slightly significant. Furthermore, school efficiency in the Centre is affected by the percentage of full-time pupils like in primary education. However, somehow in contradiction with the previous case, this variable presents a positive relation with the efficiency score. One possible interpretation is that the long hours are too demanding for smaller children in primary education, while they are more valuable for the older ones, in lower secondary education.

In Southern Italy, beyond the contextual positive effect of female employment, the only other significant variable is the percentage of tenured teachers, and it has, as expected, a positive effect.

\section{Conclusion}

Despite a highly centralized system, Italian schools are characterized by two different dynamics that are particularly persistent in time: the variability of resources (expenditure per pupil and the number of teachers per student) and the variability of the results in terms of learning outcomes in areas such as reading and math. A significant variability between different schools in the same area suggests it may be useful to study

\footnotetext{
22 Note that in all models the interaction between "comprehensive school" and the "number of service delivery points" is not statistically significant.
} 
school efficiency and its determinants. The issue is recent in the Italian debate and the relevant literature is limited to the exploration of a restricted number of schools in a specific province or region.

In this paper, efficiency analysis has been addressed by using an INVALSI national sample of public primary and lower secondary schools, matched with information on the characteristics of the schools, their budgets and on the geographical context. Descriptive statistics and institutional features suggest the presence of three distinct groups related with the Italian geographical macro-areas (North, Centre, and South), further confirmed by specific statistical tests. The reference model DEA estimations and second-stage analysis were, therefore, conducted separately for each macro-area.

Relative efficiency scores obtained by using output-oriented VRS DEA models and bootstrap procedures show that, despite a rather high average efficiency in both primary and lower secondary education, there are significant differences in the degree of efficiency at individual school level. Keeping inputs constant, there are greater margins of improvement in primary schools respect to lower secondary schools. Moreover, in both levels of education, potential productivity gains are especially large in the South where given the same level of available resources, if all schools performed like the most efficient ones, outputs would increase about 36 percent in primary education and 28 percent in lower secondary education.

These efficiency scores can be used for benchmarking purposes, pushing schools towards better outcomes with the same amount of resources. However, the different efficiency frontiers underlying the three macro-regions suggest that such exercises make sense within the same geographical area, but not by comparing Southern schools with Northern ones. INVALSI regularly provides schools with information on the distribution of student performance in math and reading at school, province, regional, and national level. Putting these results into context by providing each school with a measure of its potential improvement-while holding inputs equal-may provide an indication on the effort that should made (and be a basis for incentive schemes). Furthermore, in some cases this could induce principals to examine other schoolswith a range of inputs similar to theirs but much better results - and understand what kind of organizational and managerial features are making them more efficient.

The second stage analysis shows that determinants of efficiency vary according to education level and macro-area, offering several interesting interpretations. Results of the second-stage Tobit estimation models point out to the fact that, contrarily to general expectations, critical financial issues which could be affecting schools (such as the persistence of a great amount of revenue arrears in their budgets and the inability to meet spending commitments with available cash) have no role as concerns their efficiency. Moreover, the number of service delivery points does not seem to count.

In general, for all macro-areas, some organizational variable and some context variable presents a statistically significant effect on school efficiency, but their sign and what they measure may suggest that different strategies are necessary to support efficiency improvements in different areas of the country.

A greater share of tenured teachers (i.e., more stability and greater experience of the staff) tends to characterize more efficient schools in various macro-areas, especially in the case of lower secondary education. Other factors, such as the share of capital investments (i.e., quality of the expenditure) or of family and private financial contri- 
butions (i.e., direct participation and involvement in the school's mission) and class size (scale economies), may also play a role. Holding all other variables equal, the share of full-time pupils seems to characterize school efficiency in the Centre of Italy albeit with a different sign depending on the level of education (negative for primary education and positive for lower secondary education), maybe hinting to the different burden that longer hours of school produce on students depending on their age. In the South and for primary education, comprehensive schools yield an unexpected negative effect, which could point out to the difficulties in implementing legislative provisions for the rationalization of schools in that area of the country.

Finally, the analysis shows that contextual features weigh on efficiency despite the fact that the school's average social and economic background (ESCS) was specified in the model as an input. Indeed, the share of immigrants and female employmentwhich determine, respectively, a negative and a positive impact-have a robust effect in most areas and levels of education. These variables are notably far from the school's control. Therefore, in addition to actions directed to the school itself, policies aimed at increasing school efficiency might also have to consider taking action on the development and involvement of the surrounding local environment.

\section{Appendix A: Additional tables}

Table 8 Descriptive statistics of provincial average input and output variables, primary education

\begin{tabular}{llcrlrc}
\hline Stats & $\begin{array}{l}\text { Teachers } \\
\text { per student } \\
(\%)\end{array}$ & $\begin{array}{l}\text { School expenditure } \\
\text { (net of salaries) per } \\
\text { student (euro) }\end{array}$ & ESCS & $\begin{array}{l}\text { Other staff } \\
\text { per student } \\
(\%)\end{array}$ & $\begin{array}{l}\text { Average } \\
\text { reading } \\
\text { performance }\end{array}$ & $\begin{array}{l}\begin{array}{l}\text { Average } \\
\text { math } \\
\text { performance }\end{array} \\
\text { North }\end{array}$ \\
Mean & 0.10 & 596.41 & -0.05 & 0.04 & 503.26 & 499.18 \\
SD & 0.01 & 115.96 & 0.19 & 0.00 & 15.57 & 18.60 \\
p25 & 0.10 & 504.30 & -0.17 & 0.03 & 498.65 & 491.63 \\
p50 & 0.10 & 584.67 & -0.07 & 0.03 & 504.94 & 500.82 \\
p75 & 0.11 & 673.14 & 0.09 & 0.04 & 510.50 & 508.19 \\
Min & 0.08 & 405.46 & -0.74 & 0.03 & 439.36 & 444.92 \\
Max & 0.12 & 887.92 & 0.30 & 0.04 & 538.60 & 548.22 \\
Centre & & & & & & 493.77 \\
Mean & 0.10 & 722.93 & 0.06 & 0.04 & 500.66 & 14.01 \\
SD & 0.01 & 222.80 & 0.18 & 0.01 & 16.80 & 483.12 \\
p25 & 0.09 & 591.01 & -0.04 & 0.03 & 484.91 & 497.11 \\
p50 & 0.10 & 645.56 & -0.01 & 0.04 & 501.95 & 502.00 \\
p75 & 0.10 & 719.29 & 0.22 & 0.04 & 508.34 & 472.37 \\
Min & 0.09 & 534.57 & -0.15 & 0.03 & 475.78 & 523.64 \\
Max & 0.11 & $1,429.91$ & 0.50 & 0.05 & 539.34 & \\
\hline & & & & & \\
\hline
\end{tabular}


Table 8 continued

\begin{tabular}{llcrlll}
\hline Stats & $\begin{array}{l}\text { Teachers } \\
\text { per student } \\
(\%)\end{array}$ & $\begin{array}{l}\text { School expenditure } \\
\text { (net of salaries) per } \\
\text { student (euro) }\end{array}$ & ESCS & $\begin{array}{l}\text { Other staff } \\
\text { per student } \\
(\%)\end{array}$ & $\begin{array}{l}\text { Average } \\
\text { reading } \\
\text { performance }\end{array}$ & $\begin{array}{l}\text { Average } \\
\text { math } \\
\text { performance }\end{array}$ \\
\hline South & & & & & \\
Mean & 0.10 & 852.91 & -0.17 & 0.04 & 490.63 & 495.49 \\
SD & 0.01 & 190.41 & 0.21 & 0.01 & 21.57 & 20.74 \\
p25 & 0.09 & 710.71 & -0.32 & 0.03 & 472.07 & 473.99 \\
p50 & 0.10 & 818.84 & -0.18 & 0.04 & 490.04 & 498.31 \\
p75 & 0.11 & 932.17 & 0.02 & 0.04 & 504.12 & 512.04 \\
Min & 0.08 & 549.09 & -0.58 & 0.03 & 452.83 & 462.04 \\
Max & 0.13 & $1,324.29$ & 0.20 & 0.06 & 551.10 & 538.48 \\
\hline
\end{tabular}

Table 9 Descriptive statistics of provincial average input and output variables, lower secondary education

\begin{tabular}{|c|c|c|c|c|c|c|}
\hline Stats & $\begin{array}{l}\text { Teachers } \\
\text { per student } \\
(\%)\end{array}$ & $\begin{array}{l}\text { School expenditure } \\
\text { (net of salaries) per } \\
\text { student (euro) }\end{array}$ & ESCS & $\begin{array}{l}\text { Other staff } \\
\text { per student } \\
(\%)\end{array}$ & $\begin{array}{l}\text { Average } \\
\text { reading } \\
\text { performance }\end{array}$ & $\begin{array}{l}\text { Average } \\
\text { math } \\
\text { performance }\end{array}$ \\
\hline \multicolumn{7}{|l|}{ North } \\
\hline Mean & 0.11 & 570.13 & 0.00 & 0.03 & 511.43 & 513.94 \\
\hline SD & 0.01 & 123.95 & 0.18 & 0.00 & 14.61 & 19.78 \\
\hline p25 & 0.10 & 496.84 & -0.14 & 0.03 & 502.62 & 503.30 \\
\hline p50 & 0.10 & 527.59 & -0.04 & 0.03 & 510.73 & 510.17 \\
\hline p75 & 0.11 & 608.56 & 0.11 & 0.03 & 517.88 & 526.56 \\
\hline Min & 0.09 & 392.13 & -0.35 & 0.02 & 484.39 & 470.98 \\
\hline Max & 0.15 & $1,090.54$ & 0.56 & 0.04 & 569.93 & 585.58 \\
\hline \multicolumn{7}{|l|}{ Centre } \\
\hline Mean & 0.10 & 620.88 & 0.07 & 0.03 & 507.17 & 508.16 \\
\hline SD & 0.01 & 226.81 & 0.13 & 0.00 & 12.19 & 12.30 \\
\hline $\mathrm{p} 25$ & 0.10 & 519.07 & -0.02 & 0.03 & 500.06 & 500.82 \\
\hline $\mathrm{p} 50$ & 0.10 & 551.25 & 0.05 & 0.03 & 507.91 & 509.86 \\
\hline p75 & 0.11 & 663.55 & 0.14 & 0.03 & 514.39 & 517.14 \\
\hline Min & 0.08 & 456.91 & -0.16 & 0.03 & 485.22 & 476.28 \\
\hline Max & 0.12 & $1,541.27$ & 0.30 & 0.04 & 532.01 & 524.63 \\
\hline \multicolumn{7}{|l|}{ South } \\
\hline Mean & 0.11 & 746.62 & -0.14 & 0.03 & 473.40 & 473.43 \\
\hline $\mathrm{Sd}$ & 0.02 & 179.16 & 0.22 & 0.01 & 23.84 & 21.13 \\
\hline $\mathrm{p} 25$ & 0.10 & 639.58 & -0.25 & 0.03 & 461.94 & 466.11 \\
\hline $\mathrm{p} 50$ & 0.11 & 706.97 & -0.14 & 0.03 & 478.42 & 475.81 \\
\hline p75 & 0.13 & 870.26 & 0.04 & 0.04 & 490.19 & 487.97 \\
\hline Min & 0.08 & 456.78 & -0.64 & 0.02 & 383.30 & 410.00 \\
\hline Max & 0.16 & $1,316.83$ & 0.31 & 0.05 & 503.56 & 503.37 \\
\hline
\end{tabular}




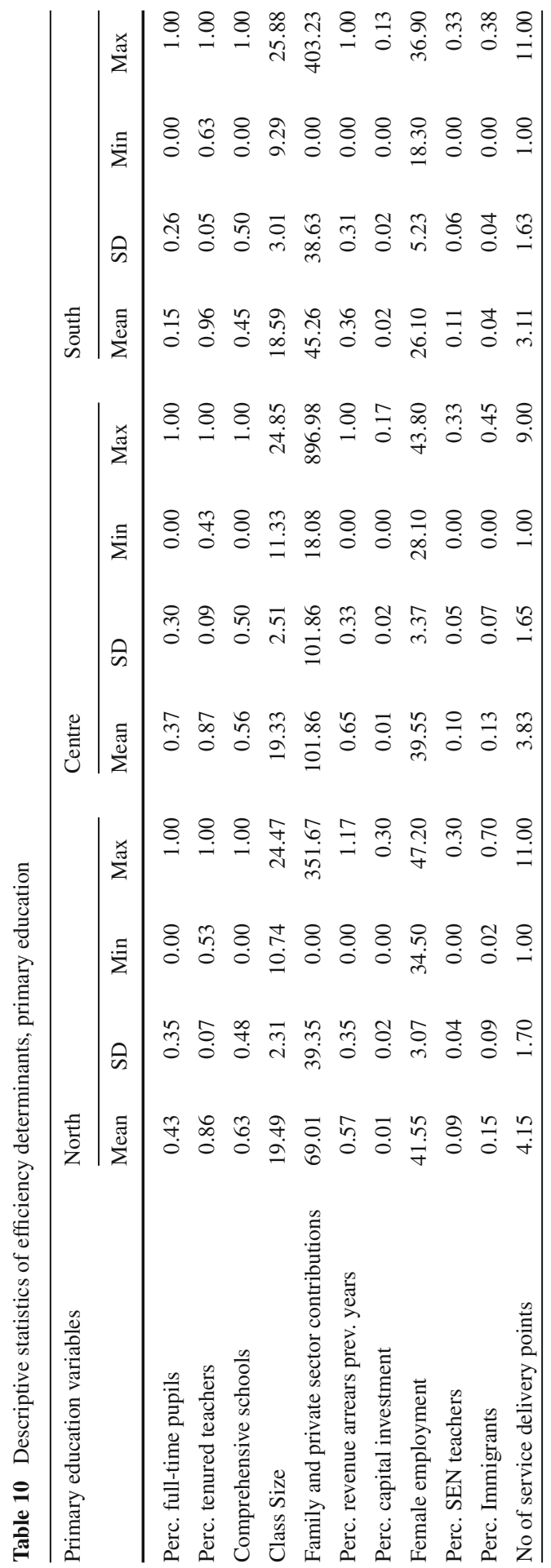




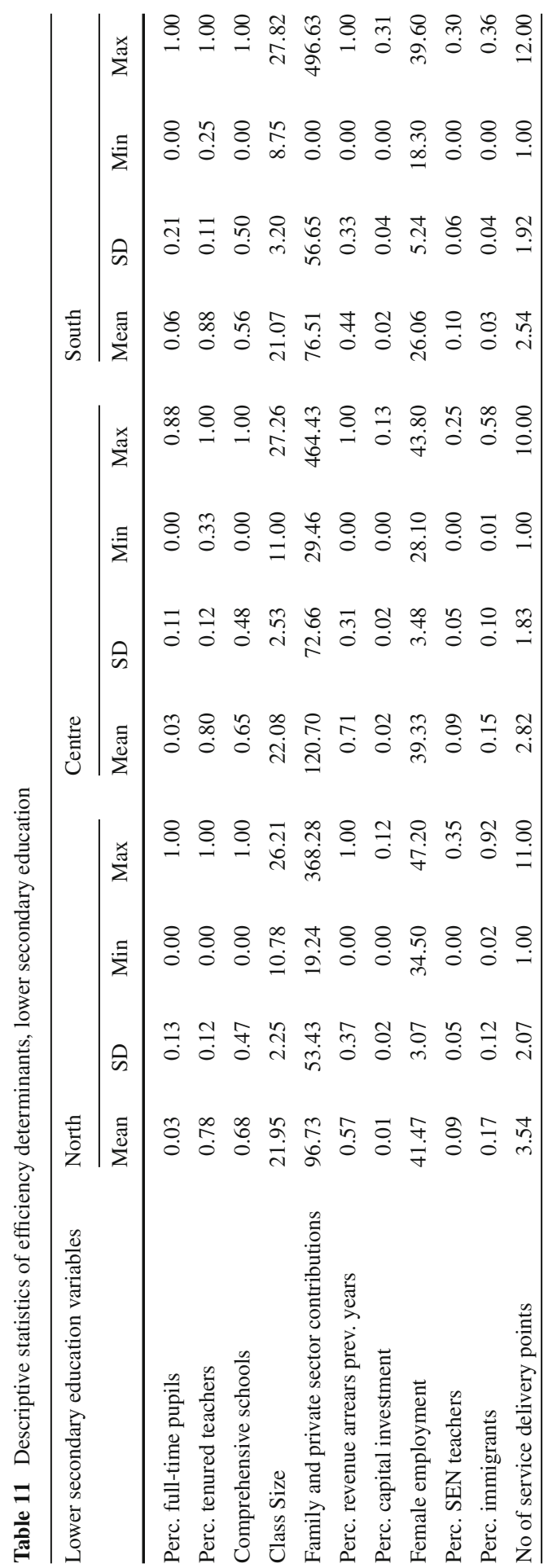


Table 12 Number of service delivery points, primary education

\begin{tabular}{|c|c|c|c|c|c|c|c|c|c|c|c|c|c|c|c|}
\hline \multirow{2}{*}{$\begin{array}{l}\text { Primary education } \\
\text { variables }\end{array}$} & \multicolumn{5}{|c|}{ North } & \multicolumn{5}{|c|}{ Centre } & \multicolumn{4}{|c|}{ South } & \multirow[b]{2}{*}{ Max } \\
\hline & N. & Mean & $\mathrm{SD}$ & $\mathrm{Mi}$ & Max & $\mathrm{N}$ & Mean & SD & $\mathrm{Mi}$ & . Max & $\mathrm{N}$ & Mean & $\mathrm{SD}$ & Min. & \\
\hline $\begin{array}{l}\text { Comprehensive } \\
\text { schools }\end{array}$ & 243 & 4.37 & 1.73 & & 11 & 140 & 4.16 & 1.74 & & 9 & 208 & 3.88 & 1.21 & 2 & 11 \\
\hline Specialized schools & 145 & 3.79 & 1.58 & 1 & 8 & 109 & 3.40 & 1.43 & 1 & 6 & 253 & 2.48 & 1.74 & 1 & 7 \\
\hline
\end{tabular}

Table 13 Number of service delivery points, lower secondary education

\begin{tabular}{|c|c|c|c|c|c|c|c|c|c|c|c|c|c|c|}
\hline \multirow{2}{*}{$\begin{array}{l}\text { Lower secondary- } \\
\text { variables }\end{array}$} & \multicolumn{4}{|l|}{ North } & \multicolumn{5}{|c|}{ Centre } & \multicolumn{4}{|c|}{ South } & \multirow[b]{2}{*}{ Max } \\
\hline & N. Mean & $\mathrm{SD}$ & Min & Max & $\mathrm{N}$ & Mean & $\mathrm{SD}$ & Min. & Max & $\mathrm{N}$. & Mean & $\mathrm{SD}$ & Min. & \\
\hline $\begin{array}{l}\text { Comprehensive } \\
\text { schools }\end{array}$ & 2584.36 & 1.85 & & 11 & 155 & 3.71 & 1.64 & 2 & 10 & 195 & 3.67 & 1.87 & 2 & 12 \\
\hline Specialized schools & 1191.77 & 1.26 & & 7 & 82 & 1.13 & 0.47 & 1 & 4 & 252 & 1.07 & 0.31 & 1 & 3 \\
\hline
\end{tabular}

\section{References}

Aaltonen J, Kirjavainen T, Moisio A (2006), Efficency and productivity of finnish comprehensive school, 1998-2004, VATT Research Reports, N.127, Government Institute for Economic Research

Agasisti T (2009) The efficiency of Italian secondary schools and the potential role of competition. A data envelopment analysis using OECD-PISA2006 data, working paper

Agasisti T, Bonomi F, Sibiano P (2012) "Adjusted" efficiency measures for schools: a two-stage empirical analysis with bootstrap DEA and tobit regression, Mimeo prepared for the $37^{\text {th }}$ annual conference of the association for education finance and policy

Barbetta GP, Turati G (2003) Efficiency of junior high schools and the role of proprietary structure. Anna Public Cooperat Econ 74(4):529-551

Bogetoft P, Otto L (2011) Benchmarking with DEA, SFA, and R, Springer and Verlag, International Series in Operations Research and Management Science, Vol. 157

Bradley S, Johnes G, Millington J (2001) The effect of competition on the efficiency of secondary schools in England. Euro J Oper Res 135:545-568

Bradley S, Taylor J (2008) Diversity, choice and the quasi-market: an empirical analysis of secondary education policy in England, Lancaster University Management School Working Paper n. 2008/23

Bratti M, Checchi D, Filippin A (2007) Geographical differences in Italian students' mathematical competencies: evidence from Pisa 2003, Giornale degli Economisti, GDE (Giornale degli Economisti e Annali di Economia), Bocconi University, vol 66(3), pp299-333, November

Brunello G, Checchi D (2006) Does school tracking affect equality of opportunity? New international evidence. Forschungsinstitut zur Zukunft der Arbeit, Bonn

Campodifiori E, Figura E, Papini M, Ricci R (2010) Un indicatore di status socioeconomico-culturale degli allievi della quinta primaria in Italia. Working paper INVALSI no 2, 2010

Charnes A, Cooper WW, Rhodes E (1978) Measuring efficiency of decision making units. Euro J Oper Res 2:429-444

Cartocci R (2007) Mappe del Tesoro. Atlante del capitale sociale in Italia, Il Mulino, Bologna

Daraio C, Simar L (2007) Advanced robust and nonparametric methods in efficiency analysis. Methodology and applications. Springer, NEw York

Essid H, Ouellette P, Vigeant S (2009) Measuring efficiency of Tunisian schools in the presence of quasifixed inputs: a bootstrap data envelopment analysis approach. Econ Educ Rev 29(4):589-596

Farrell MJ (1957) The measurement of productive efficiency. J R Stat Soc 120:253-281

Fried H, Knox Lovell CA, Schmidt S (2008) The measurement of productive efficiency and productivity growth. Oxford University Press, Oxford 
Hanushek E (2002) Publicly provided education. In: Auerbach AJ, Feldstein M (eds) Handbook of public economics. Elsevier, Amsterdam, pp 2045-2141

Hoff A (2007) Second stage DEA: comparison of approaches for modelling the DEA score. Euro J Oper Res 181(1):425-435

INVALSI (2010) Rapporto integrale sul Servizio Nazionale di Valutazione. Aspetti operativi e prime valutazioni sugli apprendimenti degli studenti, a.s, pp 2009-2010

Mancebon-Torrubia MJ, Calero J, Choi A, Ximenz-de-Embum DP (2010) Efficiency of public and publiclysubsidised high schools in Spain. Evidence from PISA 2006, MPRA Paper N. 22354

Maragos E, Despotis D (2004) Evaluating school performance over time in the frame of regional socioeconomic specificities. WSEAS Trans Math 3(3):664-670

Ministero dell'economia e delle finanze, Ministero della Pubblica Istruzione (2007), Quaderno Bianco sulla Scuola. http://www.governo.it/backoffice/allegati/36409-4157.pdf

Oliveira MA, Santos C (2005) Assessing school efficiency in Portugal using FDH and bootstrapping. Appl Econ 37:957-968

Portela MC, Camanho AS (2007) Performance assessment of Portuguese secondary school, working paper No 7

Ruggiero J (1996) Efficiency of educational production: an analysis of New York school districts. Rev Econ Stat 78:499-509

Ruggiero J, Vitaliano DF (1999) Assessing the efficiency of public schools using data envelopment analysis and frontier regression. Contem Econ Policy 17(3):321-331

Schütz G, Ursprung HW, Wößmann L (2005) Education policy and equality of opportunity, CESifo Working Paper 1518. Munich: CESifo

Simar L, Wilson PW (1998) Sensitivity analysis of efficiency scores: how to bootstrap in nonparametric frontier models. Manag Sci 44(1):49-60

Simar L, Wilson PW (2000) A general methodology for bootstrapping in non-parametric frontier models. J Appl Stat 27:779-802

Tyagi P, Prasad Yadav S, Singh SP (2008)Efficiency analysis of schools using DEA: a case study of Uttar Pradesh state in India, Working paper

Woessmann L (2003) European education production functions: what makes a difference for student achievement in Europe?, European Economy - Economic Papers 190. Directorate General Economic and Monetary Affairs, European Commission 